NBER WORRING PAPER SERIES

\title{
Transportation/Communication Considerations in the Location of Headquarters for Multi- Establishment Manufacturing Firms
}

\author{
Warren G. Lavey
}

Working Paper No. 52

COMPUTER RESEARCH CENTER FOR ECONOMICS AND MANAGEMENT SCIENCE

National Bureau of Economic Research, Inc. 575 Technology Square

Cambridge, Massachusetts 02139

August 1974

Preliminary; Not for Quotation

NBER working papers are distributed informally and in limited number for comments only. They should not be quoted without written permission.

This report has not undergone the review accorded official NBER publications; in particular, it has not yet been submitted for approval by the Board of Directors.

\section{Acknowledgments}

I am grateful to the ald of Professors John R. Meyer, Anthony G. Oettinger, and Robert $A$. Leone for guiding this research and reviewing earlier drafts of this paper. Errors are, of course, mine alone. 
Usually transportation/commuication ( $t / c$ ) considerations appear as only two in a long list of factors which determine headquarters location patterns. The research reported here singles out $t / c$ considerations as the logical basis for headquarters location decisions. The primary probe is: to what degree do transportation/comunication consideration explain the patterns of headquarters location? The case of manufacturing firms with five or more establishments and no manufacturing activity at the headquarters location was examined. The $t / c$ considerations were studied in terms of the advantages of close proximity between the headquarters of a firm and the menufacturing establishments of that firm and the advantages of close proximity between the headquarters of one firm and the headquarters of other firms. The findings. of this research show that the logic of headquarters location patterns is heavily dependent on $t / c$ considerations.

An understanding of the implication of $t / c$ considerations for headquarters logistics is a prerequisite for assessing the potential impact of changes in information and transportation technologies on headquarters location patterns and for developing policy in this area. Since industrial logistics play such a large role in determining the shape of cities ${ }^{2}$, this probe also has wider public policy interest.

\section{Introduction}

There are essentially two approaches to the analysis of the location of manufacturing firms in the logistics literature. First, progress has been made in actually describing patterns of manufacturing location, especially for urban areas. For example, Hoover and Vernon ${ }^{2}$ identify three locational zones -- core, inner ring, and outer ring -- for the New York Metropolitan Region. They go on to classify certain special industry clusters, such as communication-oriented 
industries, and begin to investigate factors in the dynamics of location decisions -agglomeration, the incubator hypothesis, and the search for space. An important spur to the quantification of these portrayals has been the development and exploitation of massive data banks. Descriptive and exploratory studies which make heavy use of data have added new dimensions to the discussion of manufacturing location. Leone's time series analysis of marginal establishments ${ }^{3}$ and the Regional Plan Association's project on the office industry in New York ${ }^{4}$ are examples of this new breed of descriptive logistics study.

The second direction of research takes a comparative cost approach to determining where industrial establishments should locate on the basis of varying factor prices. These studies create prescriptive models based on microeconomic theory and decision analysis and compare the predictions of those models with actual locational patterns. Isard follows the comparative cost approach on the national level by looking at regional cost differentials for the petrochemical, iron and steel, and aluminim industries. ${ }^{5}$ Similarly, Kemper uses regression analysis to relate the locations of industry births to sixteen industry characteristics in five zones of the New York Metropolitan region. 6 Daly and Webber review much of the prescriptive models literature dealing with industrial distributions in cities ${ }^{7}$.

Both of these approaches to logistics stress the importance of $t / c$ considerations. Some examples from each approach will be presented. On the descriptive side, Leone conjectures that ${ }^{8}$ :

communication advances appear to be weakening the spatial ties between establishments in multiestablishment firms, thereby facilitating the process of land use specialization.

He goes on to write ${ }^{9}$ :

An important technological factor has been the improvement in communications made possible by expanded low-cost intercity telephone service and electronic data processing and transmission. Within urban areas, this has been a force for decentralization. 
In contrast with Leone's findings, the report of the Regional Plan Association points out the enduring importance of personal communication which encourages a high concentration of offices ${ }^{10}$ :

There is a clear preference of headquarters for the Manhattan Central Business District, where 80 percent of the Region's and nearly 20 percent of the nation's -- headquarters jobs are located... The determining locational factor here certainly would seem to be the facilitation of face-to-face communication by executive decision-makers in an "environment" of high intention.

Transportation/communication considerations have also been handled by the prescriptive modelers of manufacturing logistics. The following passage from Daly and Webber shows how changes in transportation and communication technologies have affected the comparative cost approach to logistics ${ }^{11}$ :

Up to the third decade of the twentieth century the Weberian least-cost location models could be applied to the intra-city case; there were considerable savings in transport costs for firms which located close to the city center and the major rail terminals... The situation has changed drastically over the past 30 years: factories have dispersed over broad areas of the city; the types of manufacturing have diversified; technological change has been rapid; the markets of metropolitan-based firms have multiplied throughout states and nations; and the manufacturing labor force has spread from the central city to the suburbs. All of this has weakened the importance of transport. costs in the firm's decision on where to locate within the city.

As a result of these changes, the locational effects of least-cost modeling had to be re-examined and the role of $t / c$ demands in those models had to be reassessed. It should be noted here that this paper will look at how $t / c$ considerations affect the decision of where headquarters locate within the United States and not within a city. Entire cities will be used as units of analysis, with no concern for location within cities.

This study will examine the $t / c$ considerations in light of the basic structure of the firm. A multi-establishment firm is made up of branch and headquarters establishments, and each establishment does or does not carry on manufacturing activities. Most previous studies ignore the structure of firms 
and deal solely with establishments. The spatial configuration of establishments of a firm is thereby neglected. However, in the study of the $t / c$ considerations in the location of the headquarters of a firm, the location of the manufacturing branches of the firm are clearly important.

The remainder of this paper is organized in four sections. The first section develops the location theory with regard to headquarters of multiestablishment manufacturing firms. The specific hypotheses which will undergo empirical testing are derived and explained in this section. The next section explains the data base used in this study. This description should make the reader aware of the possibilities and problems of the ensuing empirical analysis using this data base. Third; the empirical analysis is reviewed. Three topics are covered: (A) Procedural decisions which serve as a bridge from the abstract location theory to the use of data to test the hypotheses; (B) Empirical evidence regarding the hypotheses and various approaches to assessing the significance of the empirical results; and (C) Empirical evaluation of the macrohypothesis that the logic of headquarters location patterns is heavily dependent on transportation/communcation considerations. Finally, a brief conclusion section reviews the major findings of this research and suggests directions for future studies.

I Derivation of Five Specific Headquarters Location Hypotheses The macro-hypothesis of this research is that there exists an underlying logic in the logistics of the multi-establishment firm and that the role of $t / c$ considerations in that logic can be assessed. This research will emphasize the logic of the location of headquarters of multi-establishment firms. The following diagram presents an overview of the hypotheses examined by this research: 


\section{Figure I}

Hypotheses on the Operation of Transportation/Communication Considerations in Headquarters Location Decisions

Weak Intrafirm hypothesis: Headquarters will locate with regard to the spatial configuration of their. manufacturing establishments.

Headquarters will. locate "near" at least one manufacturing establishment of the firm.

Macro-Hypothesis:

Transportation/Comunication considerations are intrinsic to the logic of headquarters
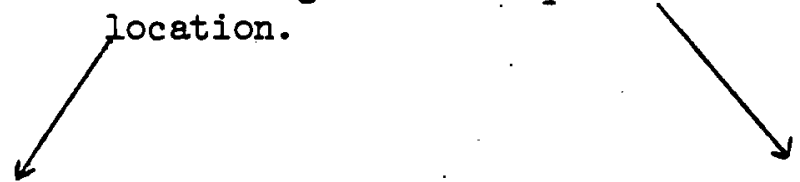

Weak Interfirm Hypothesis :

Headquarters will locate with regard to the location of other headquarters of manufacturing firms.<smiles>[TeH]</smiles>

Headquarters will locate in major cities with the headquarters of many other manufacturing firms.

Headquarters will locate in the "center" of the spatial configuration of the manufacturing establishments.

Strong Intrafirm hypothesis: Headquarters will locate "near" the "largest" manufacturing estabiishment of the firm.

Strong Interfirm Hypothesis: Headquarters will locate in the major city with the most other headquarters of manufacturing firms.

The choice of location for the headquarters of the firm must take into account both intrafirm and interfirm motives. These motives have been explained in a number of qualitative analyses of headquarters logistics. Ieone in Iocation of Manufacturing Activity in the New York Metropolitan Area points out the tension between intrafirm and interfirm motives ${ }^{12}$ : 
Whereas the advantages of a New York City location for the control function in a business have always been great, given the proximity to the financial community, access to the educational and legal establishment, and so on, in the past these advantages have frequently been counterbalanced by the diseconomies of separating control functions from operating functions.

To make the association between Leone's terms "control functions" and "operating functions" and the distinction between headquarters and manufacturing establishment activities, assume that the headquarters is concerned with control functions and the manufacturing establishments are concerned with operating functions. This point will be returned to later in the decision to look only at nonmanufacturing headquarters, that is firms which have no manufacturing activity at their headquarters locations. The Regional Plan Association study called The Office Industry: Patterns of Growth and Location points to the same two motives ${ }^{13}$ :

Manufacturing tends to be directed from a detached front office and has both strong inward (production) and strong outward (market) linkages.

Both motives depend on $t / c$ considerations as factors in the logistics of the headquarters. Before characterizing these motives more explicitly, it will be helpful to introduce one piece of logistic jargon here. The tendency for the headquarters of many firms to group together in major cities, with the headquarters of any given firm locating in a major city primarily because the headquarters of many other firms are located there, is called the agglomeration effect. The agglomeration effect has an important role in the interfirm motive.

An explicit definition of the two motives, with the appropriate interpretation of the $t / c$ considerations, can now be stated:

Intrafirm Motive: the purpose of the headquarters is to tie together and coordinate the manufacturing establishments of the firm. In this case, one would be interested in the location of the headquarters with respect to the manufacturing establishments of the firm. The exchanges and information flows 
are between the headquarters and the manufacturing establishments of the firm. The cost and effectiveness 14 of these exchanges and information flows can be influenced by the location of the headquarters.

Interfirm Motive: the purpose of the headquarters is to solicit business for the firm, secure necessary inputs for the firm, and provide connections with other firms. Here one would be interested in the location of the headquarters with respect to major cities where there will be an agglomeration of headquarters. The exchanges and information flows are between the headquarters of the given firm and the headquarters of other firms. The cost and effectiveness of these exchanges and information flows can be influenced by the location of the headquarters of the given firm.

The statements of two hypotheses follow directly from the definition of the intrafirm and interfirm motives. These hypotheses will be referred to as the weak hypotheses derived from the two motives.

Weak Intrafirm Hypothesis: headquarters will located with regard to the spatial configuration of their manufacturing establishments. The patterns of headquarters locations will show that the location of the headquarters of a firm is chosen to be either in close proximity to at least one of the manufacturing establishments of the firm or toward the center of the spatial configuration of the manufacturing establishments.

Weak Interfirm Hypothesis: headquarters will locate with regard to the location of headquarters of other manufacturing firms. The patterns of headquarters locations will show that the location of the headquarters of a firm is chosen to be in close proximity to many other manufacturing headquarters and hence in one of the major commercial cities of the country. 
Each of these weak hypotheses can be strengthened in specificity. If the intrafirm motive is a valid primary interpretation of the logic underlying the location of the headquarters for multi-establishment firms, then the headquarters should be located either "near" at least one of the manufacturing establishments of the firm or toward the "center" of the spatial configuration of the manufacturing establishments. (The research approach to the concepts of distance and centrality, given the limitations of the available data base, will be discussed in section III-a.) If the headquarters must be "near" at least one of the manufacturing establishments, is there any particular estabilishment it should be "near" more often than any other? If one establishment must be chosen, the most obvious justification on the conceptual level exists for assuming that it must be the "largest" manufacturing establishment. (The handling of size will be discussed in section III-a.) Two lines of reasoning are presented for the derivation of this strong intrafirm hypothesis:

Infrafirm Consideration Justification: this pattern may yield closer contact between administration personnel and the most important and/or greatest number of operation personnel with lower exchange and information flow cost and higher effectiveness. The cost and effectiveness are related to the transportation and communication of: (I) services provided by the headquarters for the manufacturing establishments; and (2) information demands made of the manufacturing establishment by the headquarters. Other characteristics of the manufacturing establishments being equal, both of these regards should increase with the size of the manufacturing establishment. Furthermore, the cost should increase and the effectiveness decrease with the distance from the manufacturing establishment to the headquarters. 
Interfirm Considerations Justification: the need to interface with other firms in the supply of inputs and the marketing of outputs will be greater for the largest manufacturing establisbment. These are the types of services provided by the headquarters. Also, the firm's demands for interfaces with other firms will more likely center about the largest manufacturing establishmenthan any of the smaller manufacturing establishments.

Note that in this case the interfirm considerations justification operates on a secondary level and has nothing to do with the agglomeration of headquarters. Instead, the interfirm considerations here recognize the need of the operating functions of a manufacturing establishment to interface with other firms, with this interface usually carried out via the headquarters.

Other stronger forms of the intrafirm motive, such as that the firm will locate its headquarters "near" the highest concentration of its manufacturing establishments, are possible but will not be explored in this paper.

Next, examine the stronger form of the interfirm motive. Following the agglomeration effect leads to this hypothesis: the major city with the most headquarters of manufacturing firms will have many more headquarters than any other major city. From the logic of the agglomeration effect, the process resulting in this situation is as follows: let $A$ and $B$ be two major cities with the number of headquarters of manufacturing firms in A greater than the number in $B$. Firm $X$ has to decide where to locate its headquarters. If $X$ emphasizes the interfirm motive, it will choose to locate its headquarters in some major city to be close to the headquarters of firms with which it interacts ${ }^{15}$. Assume that $X$ has only $A$ and $B$ from which to choose for the location of its headquarters in a major city. Then, all other factors such as the distribution of 
headquarters by industry and size being equal for $A$ and $B, X$ will choose to locate in $A$ because, under the interfirm motive, $X$ wants its headquarters to be near as many other headquarters as possible. Hence, the number of headquarters in $A$ has increased both absolutely and relative to $B$. Finally, there will be a tipping phenomenon, and several headquarters in B may choose to move to A for the same reasons of the interfirm motive, while any reverse flow would be unlikely. Of course in the real world major cities do offer certain regional advantages, and they do differ in the distribution of-headquarters by industry. These aspects also influence the super-agglomeration forces, that is the forces which lead to an extremely heavy concentration of headquarters in one city. This form of the strong interfirm motive can also be analyzed from the perspective of models of micromotives and macrophenomena ${ }^{16}$ and gravity and potential models ${ }^{17}$.

The statements of the strong hypotheses derived from the intrafirm and interfirm motives will be summarized as follows:

Strong Intrafirm hypothesis: headquarters will locate with regard to the location of their "largest"manufacturing establishments. The patterns of headquarters locations will show that the location of the headquarters of a firm is chosen to be in close proximity to the "largest" manufacturing establishment.

Strong Interfirm Hypothesis: headquarters will locate with regard to the location of the greatest number of headquarters of other manufacturing firms. The patterns of headquarters locations will show that the location of the headquarters of a firm is chosen to be in the major city with the greatest number of headquarters of other manufacturing firms, which will have far more headquarters of manufacturing firms than any other city. 
The data provided by Dun \& Bradstreet's Marketing Services Division called Dun's Market Identifiers (DMI) enable micro-analysis of multi-establishment manufacturing firms. The DMI file contains essentially five types of information on establishments relevant for the analysis of this paper ${ }^{18}$ :

(1) Iine of Business: by Standard Industrial Classification (SIC) number

(2) Size: by Annual Sales Volume, Number of Employees, and Net Worth

(3) Location: by State, Standard Metropolitan Statistical Area (SMSA), County, City, or Zip Code

(4) Activity: by manufacturing or non-manufacturing establishment

(5) Relation of this establishment to a firm: by single establishment firm, headquarters, or branch

Without the support of the DMI file, it would have been impossible to pursue this research. No ther computer analysis oriented data source provides such detail on manufacturing establishments and allows the researcher to deal with establishments both individually and grouped by firms. Nevertheless, it is important to keep three shortcomings of the DMI file in mind when reviewing the research design and conclusions of this study. The three problem areas are: (1) file accuracy; (2) the concept of distance; and (3) the nature of the multi-establishment firm.

(1) File Accuracy: Spot checks of corporate annual reports and Moody's Industrial Manual show that the DMI file misses some establishments but has no establishments not reported in the other sources. Part of the problem may be in the hazy definition of what constitutes a manufacturing establishment. Different sources use different criteria. For example, an establishment that is primarily a warehouse may be called a plant by Moody's but not qualify as a manufacturing establishment for DMI. It is hard to say which is the more reliable source and how exactly a plant differs from a manufacturing establishment. 
Although potential file inaccuracy is a serious difficulty, the basic findings of this research would not be adversely affected by the types of discrepancies found. All reporting of headquarters and branch locations in the DMI file agrees exactly with statements of corporate annual reports and Moody's. Any additions of manufacturing establishments to the file data on a firm would strengthen the statistical results, as will be seen in section III-C. (2) Concept of Distance: although the DMI file codes the location of each establishment by five different spatial units, no ready means of calculating the distance between establishments is built into the file. Beneath the technical problems of adding to the file geographical distances or coordinates lies a level of conceptual difficulties. Does it make sense to use geographic distance to measure how "near" one establishment is to another? Why not use air or land travel time? ${ }^{19}$ Why not use transportation or communication costs as indicators of the readiness for inter-establishment linkage? More thought is required on this problem, and it is probably true that no simple addition to the DMI file could completely satisfy the requirement for a useful measure of distance. This problem will limit the evaluation of the intrafirm motive, as will be seen in section III-A.

(3) Nature of the Multi-establishment Firm: the SIC codes of the establishments in a multi-establishment firm give some indication of whether a firm is vertically or horizontally integrated. However, there is no information about the inter-relationship of the manufacturing establishments in a firm, the interaction between the headquarters and each establishment of the firm, or the linkage between the headquartiers of one firm and the headquarters of other firms. Certainly, the degree of linkage between the headquarters and a manufacturing establishment of the firm varies across manufacturing establishments and is not solely dependent on the size of the manufacturing establishment. However, no 
information on these relationships exists in the DMI file. Once again, this is as much a conceptual problem as a data problem. Difficulties arising from this limitation are noted in sections III-A and III-C.

\section{Empirical Testing of the Locational Hypotheses}

A. Procedural Decisions

The transition from the construction of hypotheses for headquarters location to the testing of the hypotheses via the DMI file required four procedural decisions. Those decisions concerned: (1) which manufacturing firms to include in the analysis; (2) handling of subsidiaries; (3) use of spatial or geographic units instead of distances; and (4) measurement of the size of establishments. Each of these decisions will be briefly reviewed.

(1) Which manufacturing establishments to include in the analysis:

a multi-establishment firm is defined as any firm with two or more establishments. This study only looks at a subset of multi-establishment firms, those with five or more establishments and with non-manufacturing headquarters. The decision to look at those firms with non-manufacturing headquarters was made in order to strengthen the association between headquarters location and solely the location of the control functions of the firm. One can conjecture without too much abstraction from reality that the firms with non-manufacturing, or separate, headquarters locations respond purely to the intrafirm and interfirm motives and the $t / c$ considerations therein. On the other hand, the analysis of those firms which do some manufacturing at their headquarters location must include questions dealing with where to locate a manufacturing establishment. Leone includes in the questions forfthe location of a manufacturing establishment measures of 20 : 
(1) Material assembly requirements;

(2) Labor assembly needs by skill;

(3) Land assembly needs with specification of any topographic requirements;

(4) The reletive importance of face-to-face interaction with suppliers and customers;

(5) inter- and intra-city transportation requirements; and

(6) Service assembly needs.

Although some of these location factors overlap with the "pure" headquarters location factors, they are far from the logic of the intrafirm and interfirm motives. To rephrase this point, the goal of this research project is to find out to what degree simple $t / c$ considerations can explain headquarters location. It is understood that these considerations are not the only location factors for any headquarters, non-manufacturing or manufacturing. Nevertheless, it will be much simpler to assess the importance of $t / c$ considerations in headquarters location decisions in the case of non-manufacturing headquarters where these considerations should have a much greater weight than in the case of manufacturing headquarters. If they are minimal under these "pure" restrictions, they are even less likely to be important in the "mixed" case. Finding a significant effect in the pure case leaves open the option to assess the mixed case.

Unless the sample size were intolerably reduced by the assumption of separate headquarters, it would be unwise to pollute the $t / c$ considerations at this time. As a result of this decision, 1568 manufacturing multi-establishment firms with separate headquarters locations were selected.

The other component of the restriction is the limitation to firms of five or more establishments. The underlying proposition is that multi-establishment firms with large numbers of establishments are fundamentally different from those of a small number of establishments. Firmbith a large number of establishments are, in general, less localized, have a more dispersed spatial configuration of establishments, and have a higher magnitude of intrafirm and 
interfirm demands on the headquarters. The role of $t / c$ considerations seems Iikely to assume a greater weight in the location factors for the headquarters of a large multi-establishment firm. The decision to use five as the dividing line between small and large multi-establishment firms was somewhat arbitrary and intuitive. Once again, unless the sample size would become intolerably small, it would be advantageous to limit the sample in this analysis to those firms having a heavier dependence on $t / c$ considerations in the choice of headquarters location. This decision reduced the total sample of 1,568 multi-establishment manufacturing firms with separate headquarters in the DMI file to a aample of 263 firms with five or more establishments for the zear 1971.

(2) Handling of subsidiaries: the data of the DMI file allow the researcher to distinguish establishments of a non-affiliated firm, a subsidiary firm, and a parent firm. The analysis which follows combines these three types of firms. If a firm of any one of these three types has five or more establishments and a separate headquarters location, it was included in this analysis. The findings show that it may have been wiser to limit the analysis to non-affiliated firms or to find an alternative way of regarding the location of the headquarters of a subsidiary or parent firm. This aspect of the findings will be pointed out later in section III-C.

(3) Use of spatial units instead of distances: as was explained in section II, the concept of distance between establishments is very tricky on the theoretical level, and no measures of distance or locational coordinates are included in the DMI file. Yet, it was noted in the section on locational theory that some approach to the closeness of two establishments is vital for testing the hypotheses, especially those dealing with the intrafirm motive. As a surrogate for distance, this analysis will ask whether or not two establishments are in the same spatial unit. Recall that the DMI file codes each establishment 
by five spatial units -- state, SMSA, county, city, and zip code. Analysis of whether the headquarters of a firm is "near" any manufacturing establishment of that firm was conducted on two levels: (I) Is any manufacturing establishment in the same state is the headquarters? and (2) Is any manufacturing establishment in the same city as the headquarters? Obviously, disproportionate weight is given to the boundary lines between states and cities by this method. This procedure is far from totally satisfactory for an exact analysis of the logistics of headquarters, but it will suffice for the present initial analysis of the intrafirm and interfirm motives.

In order to compensate for the spillover of certain metropolitan areas beyond city and state boundaries, two special units were defined. If two establishments are in the same special unit, then they are counted as being in the same state and in the same city. The first special unit encompasses the New York Metropolitan Area. The twenty-two counties in New York, New Jersey, and Connecticut named by Hoover and Vernon in Anatomy of a Metropolis ${ }^{21}$ were combined to comprise this special unit. The second special unit covers the Chicago Metropolitan Area. This area extends over eight countries, six in Illinois and two in Indiana. Additional special units, to cover such interstate metropolitan areas as Philadelphia, Pennsylvania - New Jersey and Kansas City, Missouri - Kansas, may be useful in future research.

One consequence of the replacement of measures of distance by spatial units is that it is not possible to analyze centrality. Analysis of whether headquarters follow the form of the weak intrafirm hypothesis stating "locate in the 'center' of the spatial configuration of manufacturing establishments" is beyond the scope of this study. Hence, it will only be possible to identify those firms with headquarters in the same spatial unit as a manufacturing establishment as firms following the $t / c$ considerations of the weak intrafirm hypothesis. This approach may affect the evaluation of that hypothesis. 
(4) Measurement of the size of establishments: section II mentioned that the DMI file has three types of size indicators -- annual sales volume, number of employees, and net worth. However, annual sales volume and net worth data only apply on the firm level. For multi-establishment firms, the only size indicator on each establishment is the number of employees. Still, this indicator is quite saitsfactory for present purposes. Given this indicator of size, the "largest" establishment in the firm refers to the establishment of the largest employment size.

\section{B. Empirical Results}

Four hypotheses derived from the intrafirm and interfirm motives in section I and further defined in section III-A will be empirically examined bere. The macro-hypothesis will be tested in section III-C. Before proceeding with the findings, it is important to make one additional distinction clear. Each of the four hypotheses makes certain predictions about the locational patterns of headquarters. However, finding that the behavior of a firm corresponds to the prediction of one of the hypotheses does not necessarily mean that the firm is consciously locating with regard to the $t / c$ considerations of the hypothesis. In other words, there is a certain element of randomness of behavior which may be mistaken for sensitivity to $t / c$ considerations. The headquarters of a firm may just happen to be in the same state as a manufacturing establishment of the firm with no regard for the intrafirm motive. Likewise, the headquarters of a firm may just happen to be in a major city wi.th no regard for the interfirm motive. Use the phrase behaving in acord with the predictions of an hypothesis to refer to any firm whose behavior corresponds to the predictions of an hypothesis, regardless of intent. Use the phrase following an hypothesis to refer to any firm whose behavior corresponds to the 
predictions of an hypothesis by design rather than by random chance.. Various null models will be proposed in the analysis of the findings to try to distinguish firms following an hypothesis from all others.

The mode of presentation of each hypothesis has three components. First, the hypothesis is stated and a table of the empirical findings which will be used to test the hypothesis is shown. Note that the findings are not an adequate test in and of themselves. Next, a null model or set of mull models is used to distinguish firms following the hypothesis from those behaving in accord with the hypothesis but by chance. Finally, some general conclusions about the hypothesis will be stated based on the comparison between the null models and the actual occurrences of firms behaving in accord with the predictions of an hypothesis. This order will be modified slightly for the joint testing of the weak and strong intrafirm hypotheses.

This research will show that there is convincing support for all four hypotheses -- weak intrafirm, strong intrafirm, weak interfirm, and strong interfirm. The $t / c$ considerations of those hypotheses play major roles in headquarters location decisions.

Hypothesis I: (Weak Intrafirm Hypothesis) Headquarters will locate "near" at least one manufacturing establishment of the firm. Two levels of spatial units, state and city, are used in the analysis of whether the headquarters is close to a manufacturing establishment of the firm. Recall that the two special units for the New York and Chicago Metropolitan Areas are used in this analysis. Table 1 displays the results for the 263 manufacturing firms with five or more establishments and a separate headquarters location, with firms distributed by the number of establishments in the firm. 
Data on the Weak Intrafirm Hypothesis:

Headquarters. Locating Near Some Manufacturing Establishment of the Firm

Establishments in $\mathrm{firm}$

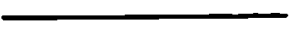

5

6-10

$11-15$

$16-20$

$21-25$

$26-30$

$31-40$

41-50

$51-60$

$61-70$

71-136
Total firms

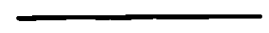

29

99

40

25

18

22

23

9

3

6

$\frac{9}{263}$
Firms with headquarters in same state as at least one manufacturing establishment

19

73

25

23

16

10

12

8

3

- 6 .

$\frac{7}{202}$
Firms with headquarters in same city as at least one manufacturing establishment

25

49

27

13

14

9

9

6

3

3

$\frac{7}{145}$ 
It is tempting to jump to the conclusion that the hypothesis is satisfied for both spatial units. It seems to be especially obvious that firms with a high number of establishments behave in accord with the predictions of the hypothesis. However, to conclude that firms with a high number of establishments have a greater propensity to follow the weak intrafirm motive just from these figures may be misleading since firms in the higher categories simply have more establishments spread around than those in lower categories. A strong null model, based on these figures, and the results for the next hypothesis together will help estimate the number of firms following the weak intrafirm hypothesis. The data for the next hypothesis will be presented before the application of the null model and statement of general conclusions about the weak intrafirm hypothesis.

Hypothesis II: (Strong Intrafirm Hypothesis) Headquarters will locate "near" the manufacturing establishment of the largest size of the firm. Table 2 displajs the findings for the predictions of this hypothesis. 
Data on the Strong Intrafirm Motive: Headquarters Locating Near the Largest Manufacturing Establishment of the Firm

Establishments in firm

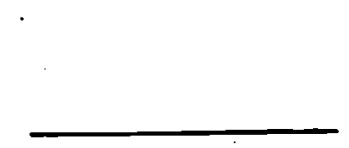

5

$6-10$

$11-15$

$16-20$

$21-25$

$26-30$

$31-40$

$41-50$

$51-60$

$61-70$

$71-136$
Total firms

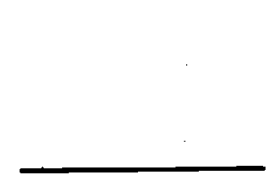

29

99

40

25

18

12

13

?

3

6

$\frac{9}{263}$
Firms with headquarters in same state as the manufacturing establishment of largest employment size

10

33

11

8

3

1

0

2

2

1

$\frac{0}{71}$
Firms'with headquarters in same city as the manufacturing establishment of largest employment size

6

18

7

1

3

1

0

2

2

0

$\frac{0}{40}$ 
A combinatorial argument will be uṣed to develop a more exact approach to the evaluation of the results for hypotheses I and II. The point of this approach is that not all firms behaving in accord with the predictions of the hypotheses need necessarily be following the intrafirm motive. Also, it is not possible by casual observation to determine which firms are only following the weak intrafirm hypothesis and which are also following the strong intrafirm hypothesis.

The argument starts by assuming that there are three possible decision rules which a firm may use with regard to the intrafirm motive:

Decision Rule \#1. Locate the headquarters randomly; without regard for the location of the manufacturing establishments of the firm.

Decision Rule \#2. Locate the headquarters in the same state as any manufacturing establishment, without regard for the size of the manufacturing establishment.

Decision Rule \#3. Locate the headquarters in the same state as the manufacturing establishment of the largest employment size.

The state was chosen as the spatial unit because it facilitates the ensuing combinatorial argument. Mathematical details of the null model are presented in Appendix A. The null model estimates the number of firms following each of the three decision rules for firms grouped by the number of establishments per firm. The model works on the type of data presented in Tables 1 and 2. Results of the null model estimates for firms with five to nineteen establishments per firm are given in Table 3. Due to the small sample size for firms with more than nineteen establishments, the model tended to break down for the higher establishments per firm categories ${ }^{22}$. 


\section{Table 3}

Application of the NuIl Model to Data on Weak and Strong Intrafirm Hypothesis: Estimates of Firms Following Decision Rules \#1, \#2, and \#3

Establishments in firm

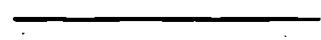

5

6

7

8

9

10

11

12

13

14

15

16

17

18

19
Percent of firms following Decision Rule \#1

37.4

32.8

29.4

25.6

45.7

27.7

52.5

32.2

42.5

55.7

66.3

0.0

55.3

28.2

$\underline{0.0}$

35.3
Percent of firms following Decision Rule \#2

38.9

34.3

49.4

29.4

44.5

65.4

38.5

21.6

$-\quad 27.6$

34.0

10.9

77.3

6.3

56.2

26.8

37.5
Percent of firms following Decision Rule $\$ 3$

23.7

33.0

21.2

45.0

9.8

7.0

9.0

47.2

29.9

10.2

22.0

22.7

38.4

15.6

$\underline{73.2}$

27.2

Mean: 
Two conclusions will be drawn from this analysis. First, the weak intrafirm motive has a great deal of influence on location decisions for headquarters. According to the null model, a mean of $64.7 \%$ of the firms with five to nineteen establishments and separate headquarters follow the weak intrafirm hypothesis. In only four of the fifteen size categories does a majority of firms behave randomly, i.e. without regard for the basic intrafirm motive. Note also that the correspondence between the percent of firms following Decision Rule \#I and the number of establishments per firm is weak. Second, the strong intrafirm motive also has a large role in the logic of headquarters location. In fact, the null model shows that in six of the fifteen size categories the percent of firms following the strong intrafirm motive, Decision Rule \#3, is higher than the percent of firms following the weak but not strong intrafirm motive, Decision Rule \#2. Once again, there is no powerful correlation between the percent following Decision Rule \#3 and the number of establishments per firm. More analysis in the direction of determining the mean percent of establishments in the same state as the largest establishment of a firm would be necessary in further evaluation of the strong intrafirm hypothesis.

This concludes the analysis of results pertaining to hypotheses I and II. 
Hypothesis III: (Weak Interfirm Hypothesis) Headquarters will locate in major cities with the headquarters of many other firms. The following ten cities with the highest number of headquarters of manufacturing firms with five or more establishments and separate headquarters will be used as the major. cities for this analysis. Listed by frequency of headquarters location in that city, these ten are:
(1) New York Metropolitan Area
(2) Pittsburgh
(3) Chicago
(4) Cincinnati
(5) Dallas
(6) Denver
(7) San Francisco
(8) St. Louis
(9) Houston
(10) Boston

The actual frequencies of headquarters location in each major city will be given as part of the analysis of hypothesis IV. Table 4 displays the results of the analysis which used these ten cities: 


\section{Table 4}

Data on the Weak Interfirm Hypothesis:

Headquarters Locating in Some Major City

Establishments

in firm

5

$6-10$

$11-15$

$16-20$

$21-25$

$26-30$

$31-40$

$41-50$

$51-60$

$61-70$

$71-136$
Total firms

29

99

40

25

18

12

13

9

3

6

$\underline{9}$.

263
Firms with headquarters in one of the ten major cities

\section{9}

73

29

20

14

8

10

6

1

5

8

193 
As in the analysis of hypotheses. I and II, it can be very misleading to make claims from these data without an adequate null model. Two slightly. different null models will be applied in testing hypothesis III.

The first null model proposes that the behavior of the manufacturing establishments can be taken as a predictor of headquarters behavior. In other words, this null model ignores the $t / c$ considerations which, by the interfirm motive, are especially important to headquarters and guide headquarters to locate in the ten major cities. A fourth decision rule for headquarters location is derived from this null model:

Decision Rule \#4. Locate the headquarters in major cities with the same frequency as manufacturing establishments.

The second model assumes that the headquarters behave like the average establishment, regardless of the presence or absence of manufacturing activity, with regard to location in the major cities. Here the $t / c$ considerations of the interfirm motive are assumed to apply equally to both types of establishments, manufacturing and non-manufacturing headquarters. A fifth decision rule to cover this situation is:

Decision Rule \#5. Locate the headquarters in major cities with the same frequency as any establishment.

Appendix B provides the details of the construction and application of these null models. Although the null models could have been applied by category for number of establishments per firm, only the aggregate findings will be shown here. Null Model I estimates that there are 11.3 firms following Decision Rule \#4. Null Model II estimates that there are 20.5 firms following Decision Rule \#5. This chart summarizes the results of this analysis: 
Firms following the basic interfirm motive

Firms behaving in accord with the predictions of the basic interfirm motive (1) 193
Column (1) minus estimate of firms following. Decision Rule \#4 (2)

181.7
Column (1) minus estimate of firms following Decision. Rule \#5

(3)

172.5

The conclusion is that well over a majority of firms, either $69.0 \%$ or $65.6 \%$, follow the weak interfirm motive. Headquarters are strongly attracted to the major cities for the types of $t / c$ considerations of the weak interfirm motive.

Now proceed to hypothesis IV, the strong form of the interfirm motive.

Hypothesis IV: (Strong Interfirm Motive) Headquarters will locate such that the major city with the most headquarters of manufacturing firms will have many more headquarters of manufacturing firms than any other major city. Table 5 shows the tabulations for each of the ten major cities used to test the extended interfirm motive in hypothesis IV. 


\section{Table 5}

Data on the Strong Interfirm Hypothesis:

Headquarters Locating in the Major Cities by City

\section{City}

New York Metropolitan Area

- Pittsburgh

Chicago Metropolitan Area

Cincinnati

Dallas

Denver

San Francisco

St. Louis

Houston

Boston
Headquarters located

in each major city

Total establishments

located in each major city

3

193.

375

30

202

43

28

21

20

54

43

12

828 
The evidence definitely suggests accepting the strong form of the interfirm motive. In fact, an interesting reflection on the strength of the super- . agglomeration effect is that of the 149 headquarters in the twenty-two counties of the New York Metropolitan Area, 141 are located in Manhattan. This evidence supports the importance of face-to-face communication in the interfirm motive. Is the strong interfirm hypothesis as well supported when the appropriate null models are applied to the data? The null models used here are analogous to the ones developed in Appendix $B$ and applied to the data from hypothesis III. Slight modifications of Decision Rules \#4 and \#5 are necessary to test hypothesis IV. The new Decision Rules state:

Decision Rule \#4-a. Locate the headquarters in the city with the most headquarters with the same frequency as manufacturing establishments.

Decision Rule \#5-a. Locate the headquarters in the city with the most headquarters with the same frequency as any establishment.

Note that the null models have changed their focus from asking how many headquarters of the 263 firms will randomly locate in the ten major cities to asking how many headquarters of the 193 located in the major cities will randomly locate in New York. The modified version of Null Model I estimates that 24.5 of the 193 headquarters located in the ten major cities will be randomly distributed in New York by Decision Rule \#4-a. Similarly, the modified version of $\mathrm{NuIl}$ Model II estimates that 36.4 of the 193 headquarters will end up in New York by Decision Rule \#5-a. The following chart presents the results of this analysis:

Firms following the extended interfirm motive

Firms behaving in accord with the predictions of the extended interfirm motive

(1) 149
Column (I) minus estimate of firms following Decision Rule \#4-a

124.5
Column (I) minus estiof firms following. Decision Rule \#5-a. 
Under either null model, a very high percent of the 193 firms, $64.5 \%$ or $58.3 \%$, follow the strong interfirm motive in locating their headquarters. The prediction of the strong interfirm hypothesis, that the largest major city will be far larger than any other in terms of number of headquarters of these firms, is obviously definitely supported by the data in Table 5.

\section{Examining the Macro-Hypothesis}

This research attempts to estimate the degree to which simple transportation/ communication considerations can explain headquarters location. of all the locational factors important to the choice of headquarters location, we want to discern whether simple hypotheses derived from only one type of locational factor, $t / c$ considerations, can be used to explain the patterns of headquarters location. In the preceding section the empirical evidence concerning each one of the four hypotheses was examined. The final question deals with the macrolevel hypothesis. That hypothesis is:

\section{Macro-Hypothesis: Transportation/Communication considerations are intrinsic} to the logic of headquarters location and can be used to explain patterns of headquarters location. This hypothesis states that all firms will include in their logistics logic the $t / c$ considerations of headquarters location. Furthermore, the macro-hypothesis predicts that the motives derived from these considerations will explain patterns of headquarters location. In other words, the macrohypothesis predicts that every firm with five or more establishments and a separate headquarters will follow the intrafirm and/or interfirm motives for headquarters location. Table 6 shows the data used to examine the macro-hypothesis. 


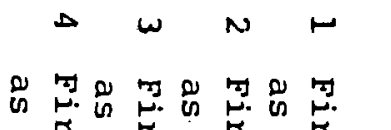

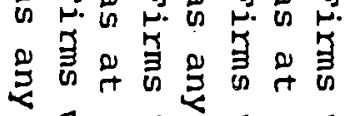

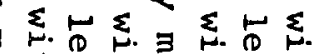

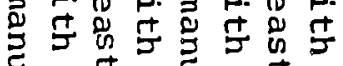

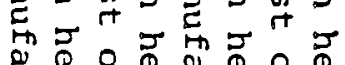
D

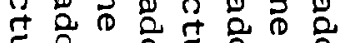
是

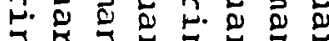

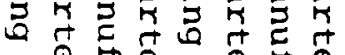
Q 020 年 ⿰幺 $\Omega$ है

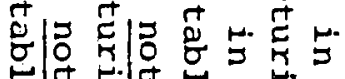

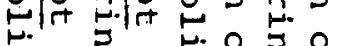
光 ⿹

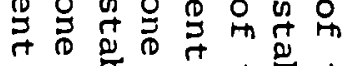

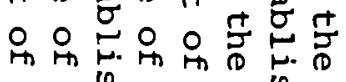

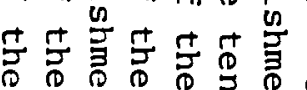

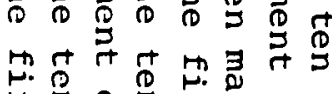

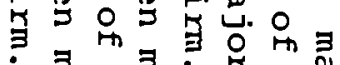

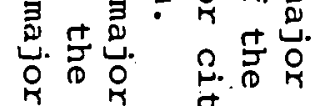

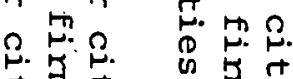
萬草

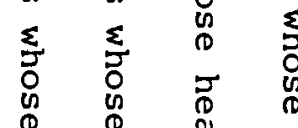

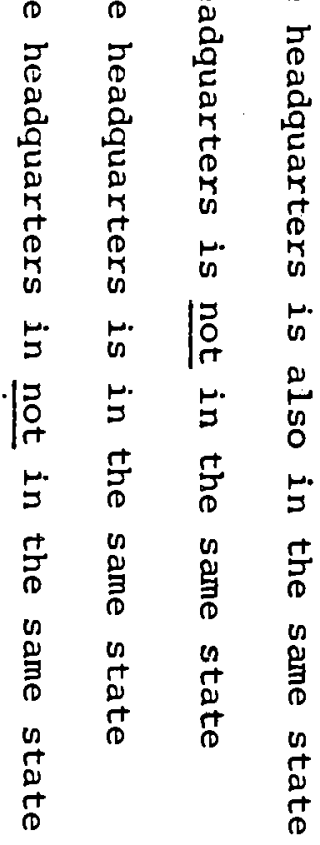
亳

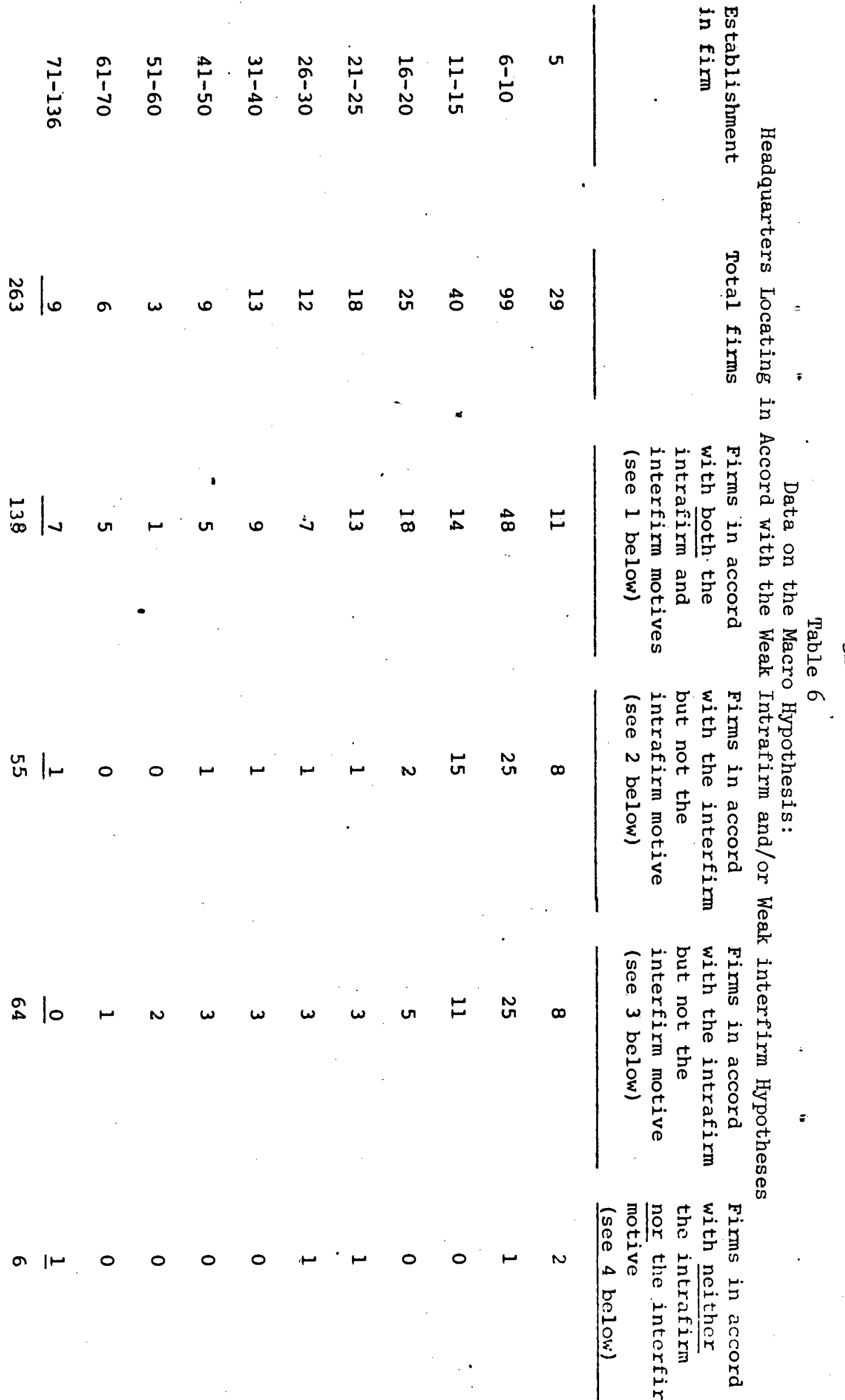


These results are startling in the power of the $t / c$ considerations which they indicate. Only 6 of the 263 firms, or $2.3 \%$, do not behave in accord with the predictions of either the intrafirm or the interfirm motives derived from the $t / c$ considerations. Of course, as the combinatorial and null models developed in the testing of hypotheses I to IV have shown, the percent of firms not following either the intrafirm or interfirm motives is definitely higher than the 2.3\%. A certain percent of the headquarters seeking neither to locate in the same state as one of the manufacturing establișments of the firm nor in a major city will end up in the same state as one of the manufacturing establishments of the firm and/or in a major city anyway. An appropriate null model for this situation is beyond the scope of this analysis. Still, it is extremely powerful for any single set of considerations to be directly related to the location patterns of so many firms.

The six firms behaving in accord with neither the intrafirm nor the interfirm motives are:

(1) Hercules Inc.

(2) Marathon Oil Inc.

(3) Textron Inc.

(4) National Gypsum

(5) CRA Inc.

(6) Colorado Mnfg. Corp.

Two characteristics of this group relate to aspects of the data base and the procedural decisions. First, the DMI file definition of a manufacturing establishment excludes certain plants of these firms. For Hercules Inc., both the headquarters and a research center are located in Wilmington, Delaware. Similarly, Marathon Oil Co., with headquarters in Findlay, Ohio, has oil and gas lands located in Ohio. If research centers and mineral lands had been classified as manufacturing establishments by DMI, both of these firms would be in accord with 
the intrafirm motive. Certainly, many of the same $t / c$ considerations embodied in the intrafirm motive apply to the types of plants not classfied as manufacturing establishments by DMI. Second, the cases of subsidiary and parent firms appear three times in the list of six firms. CRA Inc. and Colorado Mnfg. Corp. are both subsidiaries and Taxtron Inc. is a parent firm. The logic of the location of headquarters for subsidiaries and parent firms is more complicated than that of non-affiliated firms. The role of $t / c$ considerations in the headquarters location patterns for subsidiaries and parent firms should be reconsidered. Finally, it is interesting to look at the locationsof the 138 firms which behave in accord with both the intrafirm and the interfirm motives. A distinguishing characteristic of the New York Metropolitan Area emerges in the data in Table 7. 
Distribution by City of Firms in Accord With Both the Weak Intrafirm and Interfirm Hypotheses

City

Total headquarters located in city

New York Metropolitan Area

Pittsburgh

Chicago Metropolitan Area

Cincinnati

Dallas

Denver

San Francisco

St. Louis

Houston

Boston
149

11

8

4

4

4

4

3

3

3

193
Firms with headquarters in the city and at least one manufacturing establishment in the state of the city

\section{9}

11

7

1

4

4

4

3

3

2 
every firm with headquarters in Pittsburgh, Dallas, Denver, San Francisco, St. Louis, and Houston also has some manufacturing establishment in the corresponding states. The New York Metropolitan Area is the major city where 50 of the 55 firms in accord with the interfirm but not the intrafirm motive have their headquarters. The headquarters locations and names of the five other firms with headquarters in one of the ten major cities but no manufacturing establishment in the corresponding state are:

(1) Chicago -- Brunswick Corp.

(2) Cincinnati - Procter \& Gamble Mnfg. Co.

(3) Buckeye Callulose Corp. .

(4) Folger Coffee Co.

(5) Boston -- Cabot Corp.

Note that the three firms with headquarters in Cincinnati are all subsidiaries of Procter \& Gamble, a firm that has other subsidiaries with many manufacturing establishments in Ohio. Here again, we encounter the problem of how to handle subsidiaries discussed in section III-A. The concentration of headquarters in New York of firms with no manufacturing establishment in that state is further evidence of the super-agglomeration effect resulting from $t / c$ considerations. IV Conclusion

Transportation/communication considerations have been shown to explain or, at least, be associated with the headquarters location patterns of a high percent of the manufacturing firms with five or more establishments and separate headquarters location. Both the intrafirm and the interfirm motives were found to be very signficant factors in the logic of headquarters location decisions. One natural extension of this research involves applying the same hypotheses to the case of manufacturing headquarters. Two other particularly intriguing paths of research are encouraged by the strength of these results. First, from the technology point of view, it will be interesting to learn how the role of $t / c$ considerations in the logic of headquarters location decisions was changed over time. Have changes in $t / c$ 
technologies affected the importance of proximity to a manufacturing establishment of the firm for the headquarters, the intrafirm motive? How about the importance of proximity to the headquarters of other firms, the interfirm motive? Second, from the public policy point of view, it will be important to learn how the close association between $t / c$ considerations and headquarters location patterns affects what government can do to influence business logistics. Do the various strategies used to attract the headquarters office industry to a particular area make sense in light of the importance of $t / c$ considerations? Can the central business districts of major cities continue to thrive on the importance of face-to-face communication? 
1. See Hoover, E. and Vernon, R., Anatomy of a Metropolis, New York: Anchor Books, 1959. Lowry, I., A Model of Metropolis. Santa Monica: Rand, 1964. Forrester, J., Urban Dynamics. Cambridge: M.I.T. Press, 1969.

2. Hoover, E. and Vernon, R., op. cit., Chapters 1-5.

3. Leone, R., Location of Manufacturing Activity in the New York Metropolitan Area. New York: N.B.E.R., 1974.

4. Armstrong, R. (ed.), The Office Industry: Patterns of Growth and Location A Report of the Regional Plan Association. Cambridge: M.I.T. Press, 1972.

5. Isard, W.' Methods of Regional Analysis. Cambridge: M.I.T. Press, 1960. Chapter 7.

6. Kemper, P., The Location Decisions of Manufacturing Firms Within the New York Metropolitan Area. Unpublished Ph.D. dissertation. Department of Economics, Yale University, 1973.

7. Daly, M. and Webber, M., "The Growth of the Firm within the City", Urban Studies. October, 1973. p. 303-317.

8. Leone, R., op, cit., P. 1-4.

9. Ibid, p. 1-6.

10. Armstrong, R., op. cit., p. 98.

11. Daly, M. and Webber, M., op. cit., p. 304 .

12. Leone, R., op. cit., p. 1-7.

13. Armstrong, R., 으. cit., p. 69.

14. These cost and effectiveness judgments deal with the costs and benefits of the time and space factors of interpersonal communication via face-to-face, telephone, and postal media, and of transportation of personnel and goods at various locations for the headquarters.

15. Only data on the number of headquarters of manufacturing firms in a major city are available in this segment of the DMI file. It is certainly true that the presence of major financial and legal firms in a major city is of great importance in influencing the location decisions of a manufacturing firm for its headquarters. Hopefully, the presence of many headquarters of manufacturing firms in a major city would indicate the presence of the appropriate financial and legal services in the major city.

16. See Schelling, T., "On the Ecology of Micromotives", The Public Interest. Fall, 1971. Schelling, T., "Dynamic Models of Segregation", Journal of Mathematical Sociology, 1971.

17. See Isard, W., op, cit., Chapter 11.

18. See Dun \& Bradstreet Marketing Services Division, Precision Tools for the Executive: A DMI Guide. 1973. D\&B Marketing Services Division, Dun's Market Identifiers. 197.1. 
19. See Szalai, A., The Uses of Time. The Hague: Mouton Press, 1972, Chapin, F. and Logan, T. "Patterns of Time and Space Use", in Perloff, H. (ed.), The Quality of the Urban Environment. Baltimore: Johns Hopkins Press, 1970.

20. Leone, R., "The Role of Data Availability in Intrametropolitan Workplace Locations Studies", Annals of Economic and Social Measurement. April, 1972, p. 175.

21. Hoover, E. and Vernon, R., op. cit., p. 8.

22. The model will yield a negative number of firms following one or two of the decision' rules for many of the distributions of total firms, firms in accord with the basic intrafirm motive, and firms in accord with the extended

= intrafirm motive in the higher establishments per firm categoreis. This problem is more likely statistical, i.e. due to the small sample sizes in those categories, than a fault in the construction of the null model or a behavior pattern of firms in those categories.

23. Liu, C., Introduction to Combinatorial Mathematics. New York: McGraw-Hill, 1968. 
Let: $\quad x=$ number of firms following decision rule $\# 1$

$Y=$ numier of firms following decision rule $\# 2$

$z=$ number of firms following decision rule $\# 3$

$A=$ condition that the heacquarters is in the same state as at least one manufacturing establishment

$B=$ condition that the headquarters is in the same state as the manufacturing establishrent of the largest size

$\mathrm{n}=$ number of estabjishments per firm

$T=$ number of firms with $\underline{n}$ establishments and separate headquarters

$\mathrm{R}=$ number of firms behaving in accord with the predictions of the basic intrafirm hypothesis for firms of size $\underline{n}$

$\mathbf{S}=$ number of fims behaving in accord with the predictions of the extended intrafinn hypothesis for firms of size $\underline{n}$

First look at the probability of $A$ occurring for firms behaving without regard for the basic intrafirm motive, $P(\pi)$. Two different derivations of the formula for $P(A)$ will be presented. Both rely on simple combinatoric arguments of the type found in Liu, C. Introduction to Combinatorial Matnematics. chapter $l^{23}$. In both . cases the two special spatial units are treated as corrections for overlaps rather than as distinct states and no states, such as Alaska or Hawaii, are deleted. Hence, we work with fifty possible states for location.

(I) A firm with $\underline{n}$ establishments has $(n-1)$ manufacturing branches and the headquarters. There are $50^{n-1}$ ways to distribute the manufacturing branches in the fifty states, treating each establishment as distinct. There are $49^{n-1}$ ways for all (n-l) manufacturing establishments to be outside the state of the headquarters. So, $P(A)=1-\frac{49^{n-1}}{50^{n-1}}=1-0.98^{n-1}$.

(II) The same result can be established by use of the binomial theorem. If there are $i$ manufacturing establishments in the same state as the headquartcrs 
$(j=1, \ldots, n-1)$, those $j$ establishments could be chosen from the (n-1) manufacturing establishments in $c(n-1, j)$ ways. Further, the remaining $(n-j-1)$ establishments outside of the state in which the headquarters is located can be distributed in the remaining 49 states in $49^{n-j-1}$ ways. Using the rule of product and summing over all feasible $j$, the number of possible ways of obtaining $A$ is: $\sum_{j=1}^{n-1} c(n-1, j)\left(49^{n-j-1}\right)$.

$$
\text { So, the probability of } A \text { is: } P(A)=\frac{\sum_{j=1}^{n-1} c(n-1, j)\left(49^{n-j-1}\right)}{50^{n-1}} \text {. }
$$$$
\text { But, by the binomial }
$$

theorem, the numerator is just $\left(50^{n-1}-49^{n-1}\right)$. Hence, oncé again, $P(A)=1-0.98^{n-1}$.

Next evaluate $P(B)$ for firms behaving without regard for the basic intrafirm

motive - i.e. randomly. For all $\underline{n}$, there is only one largest establishment, only one headquarters, and fifty states. Then, the probability that the largest establishment will be in the same state as the headquarters is: $P(B)=1 / 50=0.02$. Note that we here disregard the case in which the separate headquarters is the largest establishment.

Finally, $P(B \mid A)$ is by definition equal to $P(B) / P(A)$ since $P(B \cap A)=P(B)$. Then, $P(B / A)=\frac{50^{n-2}}{50^{n-1}-49^{n-1}}$

The real power of this null model comes in the ability to solve for $X, Y$, and $\mathbf{Z}$ in three simultaneous linear equations. These equations are set up as:

(1) $\quad P(A)(X)+Y+Z=R$

(2) $\quad P(B)(X)+P(B \mid A)(Y)+Z=S$

(3) $X+Y+Z=T$ 


\section{Appendix B}

Nuil Models for the Interfirm Hypotheses

Let: $x=$ number of firms following the basic interfirm hypothesis $Y=$ number of firms following decision rule \#4 $z=$ number of firms following decision rule $\# 5$

There are 4,851 total establishments in the file of firms with five or more establishments and a separate headquarters location. Of those 4,851 establishments, 263 are headquarters and the remaining 4,588 are manufacturing branches. Additionally, there are 828 total establishments located in the ten major cities -- 193 headquarters and 635 branches.

The first null model specifies that the percent of firms not following the basic interfirm hypothesis which behavejin accord with its predictions is equal to the ratio of manufacturing branches in the major cities to all manufacturing branches. In other words, $\frac{635}{4,588}$ or $13.8 \%$ of the headquarters located randomly, i.e. not following the basic interfirm hypothesis, should end up in major cities anyway according the the first null model. We then have two simulataneous equations:

$$
\begin{aligned}
& \text { (1) } Y=0.138(263-X) \\
& \text { (2) } X+Y=193
\end{aligned}
$$

Solving yields:

$$
\begin{aligned}
& X=181.7 \\
& Y=11.3
\end{aligned}
$$

The second null model states that the percent of firms not following the basic interfirm hypothesis which behaves in accord with its predictions is equal to the ratio of all establishments in the major cities to the total number of establishments. In other words, $\frac{828}{4,851}$ or 17.18 of the headquarters located randomly, i.e. not following the basic interfim hypothesis, should end up in major 
cities anyway according to the second null model. While equation (2) applies to this model also, equation (1) is modified with the new ratio:

(3) $Y=0.171(263-X)$

Solving yields:

$$
\begin{aligned}
& X=172.5 \\
& Y=20.5
\end{aligned}
$$

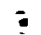

